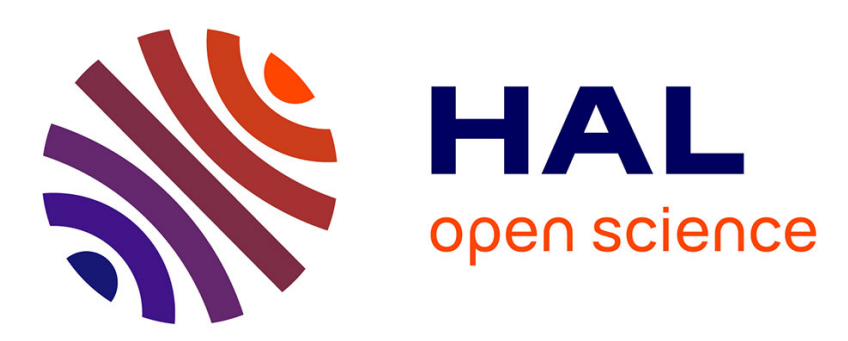

\title{
Impurity-induced microstructure of grain boundaries in cast silicon. Incidence on electrical properties
}

\author{
J.Y. Laval, J.L. Maurice, C. Cabanel
}

\section{To cite this version:}

J.Y. Laval, J.L. Maurice, C. Cabanel. Impurity-induced microstructure of grain boundaries in cast silicon. Incidence on electrical properties. Revue de Physique Appliquée, 1987, 22 (7), pp.623-629. 10.1051/rphysap:01987002207062300 . jpa-00245585

\section{HAL Id: jpa-00245585 https://hal.science/jpa-00245585}

Submitted on 1 Jan 1987

HAL is a multi-disciplinary open access archive for the deposit and dissemination of scientific research documents, whether they are published or not. The documents may come from teaching and research institutions in France or abroad, or from public or private research centers.
L'archive ouverte pluridisciplinaire HAL, est destinée au dépôt et à la diffusion de documents scientifiques de niveau recherche, publiés ou non, émanant des établissements d'enseignement et de recherche français ou étrangers, des laboratoires publics ou privés. 
Classification

Physics Abstracts

$61.70 \mathrm{~N}-72.20 \mathrm{~J}-73.90-81.10-61.70 \mathrm{~W}$

\title{
Impurity-induced microstructure of grain boundaries in cast silicon. Incidence on electrical properties
}

\author{
J. Y. Laval $\left({ }^{*}\right)$, J. L. Maurice $\left({ }^{+^{*}}\right)$ and C. Cabanel $\left({ }^{*}\right)$ \\ (*) Laboratoire de Microstructures, CNRS-ESPCI, 10, rue Vauquelin, 75231 Paris Cedex 05, France \\ $\left(^{+}\right)$Laboratoire de Physique des Matériaux, CNRS, 1, Place Aristide-Briand, 92190 Meudon, France \\ - Centre d'Etudes de Chimie Métallurgique, CNRS, 15, rue Georges-Urbain, 94407 Vitry/Seine Cedex, \\ France
}

(Reçu le 3 février 1987, révisé le 20 mars 1987, accepté le 27 mars 1987)

\begin{abstract}
Résumé. - Le rôle des impuretés dans le silicium polycristallin pour photopile est analysé et tout particulièrement pour l'aluminium et le carbone, impuretés résiduelles des méthodes Bridgman et HEM. Par combinaison des informations locales, électriques, chimiques et structurales, essentiellement en microscopie électronique en transmission, il est possible de relier l'activité et les barrières électriques à la cristallochimie du joint. Dans le cas de l'aluminium, il est montré que l'activité électrique du joint dépend de la localisation et de l'environnement du dopant. Par ailleurs, les différentes façons dont le carbone dégrade les propriétés électriques sont décrites. On considère les corrélations avec les autres impuretés dont l'oxygène et finalement le rôle prédominant des impuretés est souligné.
\end{abstract}

\begin{abstract}
The role of impurities in polysilicon for photocell has been investigated. Aluminium and carbon residual impurities in the Bridgman and HEM materials were particularly considered. The combination of local electrical, chemical and structural information with high spatial resolution, specifically in transmission electron microscopy, allowed to correlate the crystallography and chemistry with the electrical activity and barriers at grain boundaries. For aluminium it was shown that GB electrical property depends on the localization and environment of this dopant. The different ways for carbon to impair electrical properties are described. The correlation with other impurities and specially oxygen are considered and finally the predominant role of impurities is pointed out.
\end{abstract}

\section{Introduction.}

The precise interpretation of the electrical activity of grain boundaries (GBs) and defects in polysilicon is of paramount significance for optimizing photocells efficiency as well as for developing novel applications in microelectronics. This activity comes either from structural factors (dangling bonds, dislocations) or from impurities. We have been concerned by the role of impurities. Our goal was to correlate local information on impurity distribution to the carrier behaviour at grain boundaries (potential barrier for majority carriers and recombination for minority carriers).

A set of combined experiments were carried out. Marked GBs were concurrently characterized by voltage drop off measurements and by laser and electron beam induced current. In order to improve the information we have developed a scanning transmission electron beam induced current method and combined several analytical techniques.

We first examined boron in a commercial material obtained by the Bridgman method. But taking into account the high difficulty of local analyses of this element, we considered $\mathrm{Al}$, isovalent, same type dopant which is a natural impurity of silicon. This research was then carried out on a laboratory silicon prepared by the heat exchange method and carefully analysed macroscopically. Finally, we had to consider the role of carbon, main residual impurity for this material.

\section{Experimental methods.}

The materials have been prepared by the Bridgman method [1] and by the heat exchange method [2]. 
The impurities have been analysed macroscopically by neutron activation (NAA), nuclear probe analysis (NPA), by infra-red spectroscopy (IR) and charged particle analysis [3]. NAA is based on the ${ }^{27} \mathrm{Al}(n, \gamma){ }^{28} \mathrm{Al}$ reaction. The neutron irradiation of the $\mathrm{Si}$ matrix leads to an artefact signal of $\simeq 4 \times 10^{17}$ at $\mathrm{cm}^{-3}$ [4]. NPA uses a deuton microbeam. Its size is $5 \times 5 \mu \mathrm{m}^{2}$, its intensity ranges between 0.4 to $0.8 \mathrm{nA}$ and its energy is optimized at $1.45 \mathrm{MeV}$. The induced reactions are ${ }^{12} \mathrm{C}(\mathrm{d}, \mathrm{p}){ }^{13} \mathrm{C}$ and ${ }^{16} \mathrm{O}(\mathrm{d}, \mathrm{p}){ }^{17} \mathrm{O}[6]$. Grain boundary resistivity has been measured by the tungsten microelectrodes technique [7]. The electrical activity has been obtained by LBIC measurement from $\mathrm{AsGa}$ and $\mathrm{HeNe}$ laser and EBIC on $\mathrm{Al}$ coated MIS diodes [8]. Scanning transmission electron microscopy for higher spatial resolution has been carried out on thin Al coated MIS diodes with a Al-Ga ohmic contact [9].

The crystallographical and chemical analyses of grain boundaries were pursued mainly by conventional and scanning transmission electron microscopy (TEM-STEM) : high resolution, microdiffraction, $\mathrm{X}$-ray analysis (EDX) and electron energy loss (EELS). Complementary analyses were done on precipitates and GBs by SIMS using $\mathrm{Cs}^{+}$as primary ions.

One has to consider that chemical microanalyses (EDX and EELS) can only be efficient for impurity contents greater than $10^{19} \mathrm{~cm}^{-3}$, oppositely, due to the minority carrier diffusion length in these materials, electrical measurements (EBIC, STEBIC, LBIC) are only possible for dopant concentration smaller than $10^{18} \mathrm{~cm}^{-3}$. Consequently, it has not been possible to perform all the characterization on each type of sample. All these experiments have been performed on as-grown material, without any further heat treatement.

\section{Specific behaviour of carriers at grain boundaries.}

By combined electrical, chemical and structural local experiments we have been able to correlate the carrier behaviour to the type of grain boundaries. In fact, it often appears that it is not the intrinsic geometry of the boundary which is significant for the electrical properties but the chemical distribution of impurities which is nevertheless strongly related to the GB geometry. A «clean» boundary such as a low order twin boundary is not active and does not show any potential barrier. If such a twin boundary contains decorated extrinsic dislocations it becomes highly active but usually does not exhibit potential barrier due to the discontinuous distribution of defects [10].

For high order twins the situation is more complex since they may be active and resistive as well. Subboundaries behave as low order twins with decorated dislocations. General boundaries act as recombinat-

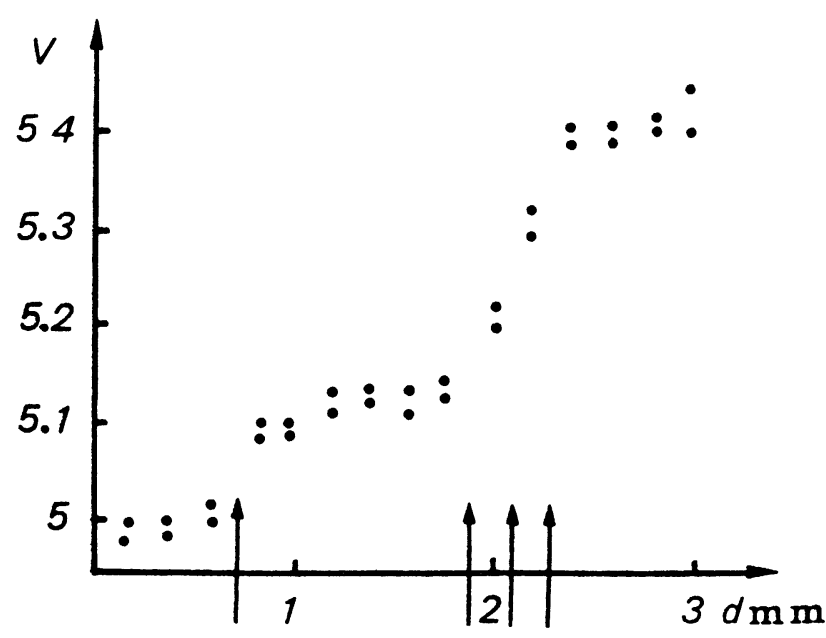

Fig. 1. - Voltage drop-off profile on an undoped Bridgman-polysilicon. (General grain boundaries are indicated by arrows). A non-intentionally doped E. G. Bridgman polysilicon. $\left(N_{\mathrm{Al}} \simeq 10^{15}\right.$ at. $\left.\mathrm{cm}^{-3}, \quad \rho=3,3 \Omega \mathrm{cm}\right) \quad N_{\mathrm{B}}=$ $5 \times 10^{15}$ at. $\mathrm{cm}^{-3}$.

ing centres as well as potential barriers (Fig. 1). In that case it is difficult to determine whether the electrical properties are geometrically or chemically induced. Considering that both signal for majority and minority carriers are not necessarily reinforced here, it might be that chemical and structural effects interact to give a weaken result.

\section{Aluminium behaviour at grain boundaries.}

3.1 GROWTH AND ELECTRICAL PROPERTIES OF Al DOPED POLY-SILICON. - Aluminium was added to the electronic-grade charge so that the final concentration in the ingot $\left(N_{\mathrm{Al}}\right)$ varied from bottom to top between $10^{17}$ at. $\mathrm{cm}^{-3}$ to $10^{20}$ at. $\mathrm{cm}^{-3}$, in good agreement with the distribution coefficient of $\mathrm{Al}$ in $\mathrm{Si}$ $\left(2 \times 10^{-3}\right)[11]$. Oxygen concentration varied from 8 to $3 \times 10^{17}$ at $\mathrm{cm}^{-3}$. Consequently, the hole concentration $(p)$ varied between $8 \times 10^{16}$ and $10^{18} \mathrm{~cm}^{-3}$, the resistivity between 0.2 and $0.04 \Omega \mathrm{cm}$, and the minority carrier diffusion length $\left(L_{\mathrm{n}}\right)$ between $12 \mu \mathrm{m}$ and less than $2 \mu \mathrm{m}$ [4]. The discrepancy between $N_{\mathrm{Al}}$ and $p$ indicates that an important part of $\mathrm{Al}$ atoms was not in the usual substitutional acceptor site. These atoms could be either in another type of sites in the perfect crystal, either in precipitates or segregated on crystalline defects. Furthermore, as the trap density responsible for the low $L_{\mathrm{n}}$ values was small $\left(10^{15} \mathrm{at} \cdot \mathrm{cm}^{-3}[12]\right)$, only a few of these non acceptor $\mathrm{Al}$ atoms would be involved in these traps. Therefore they were mainly electrically inactive.

3.2 Microstructure of the ingot. - Precipitation of $\mathrm{Al}$ was signaled by the appearance of dislocation loops in samples with $N_{\mathrm{Al}}$ value greater than $10^{19}$ at. $\mathrm{cm}^{-3}$ in good agreement with the solu- 
bility limit for $\mathrm{Al}$ in $\mathrm{Si}\left(2 \times 10^{19}\right.$ at. $\mathrm{cm}^{-3}$ at $\left.1200^{\circ} \mathrm{C}[11]\right)$. Following the growth axis of the ingot, the dislocation loop density first increased with $N_{\mathrm{Al}}$ to reach a maximum $\left(10^{8} \mathrm{~cm}^{-2}\right)$ at an ingot level corresponding to average $N_{\mathrm{Al}}=$ $8 \times 10^{19}$ at. $\mathrm{cm}^{-3}$. This maximum was found in zones were local $\mathrm{Al}$ concentration measured by EDX attained $10^{20} \mathrm{at}_{\mathrm{cm}} \mathrm{cm}^{-3}$. For higher average $N_{\mathrm{Al}}$ values, the loop density decreased to the benefit of large precipitates (several $\mu \mathrm{m}^{3}$ ).

Segregation of aluminium was detected in the grain boundaries, in samples with $N_{\mathrm{Al}}$ greater than $10^{19}$ at $\mathrm{cm}^{-3}$ (Fig. 2). Moreover as aluminium concentration varied greatly inside the same GB, the segregation happened in specific zones. Furthermore, as the detection limit was $1 \mathrm{wt} \%$ in $10^{5} \mathrm{~nm}^{3}$, it is reasonable to think that segregation most likely also occurred at lower $N_{\mathrm{Al}}$ but could not be detected with the experimental conditions used.

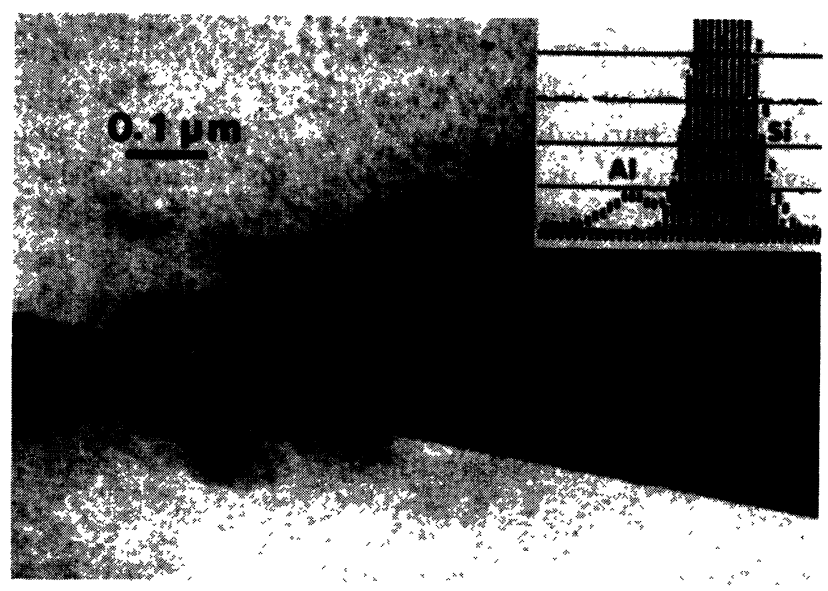

Fig. 2. - Detection of aluminium at the grain boundary by STEM-EDX of an Al doped E.G. HEM polysilicon. $\left(N_{\mathrm{Al}}=10^{19}\right.$ at. $\left.\mathrm{cm}^{-3}, \rho=3,3 \Omega \mathrm{cm}\right)$

$$
N_{\text {B }}=2 \times 10^{15} \text { at. } \mathrm{cm}^{-3} \text {. }
$$

Finally, oxygen was detected with EELS on the precipitates in the two materials [7, 8]. Taking into account that $\mathrm{Al}-\mathrm{O}$ interactions are much stronger than $\mathrm{Si}-\mathrm{O}$, it seems likely that oxygen plays a preeminent role in precipitate nucleation.

3.3 Discussion. - In a cast material, segregation can occur through two ways : the first is solidification segregation, where impurities with low distribution coefficients (e.g. : Al) concentrate in the last solidified parts at a given level in the ingot (e.g. : GBs). The second is the equilibrium segregation, where the impurity atoms concentrate in the core of the crystalline defects mainly in order to lower elastic energy [13]. In the case of an as grown ingot with a short heat treatment, however, the equilibrium process is stopped before segregation at the very core of the defects is achieved. In the studied ingot, the two processes are very likely to occur, the first being the origin of the great amounts of $\mathrm{Al}$ at GBs, and the second leading to the final localization of $\mathrm{Al}$ in specific GB zones, which would be extrinsic dislocations [4, 8]. In that case, the existence of minute precipitates seems to be most probable. This is coherent with the hypothesis of oxygen-induced nucleation and with the fact that $\mathrm{Al}$ atoms which are not shallow acceptors are, for most of them, not electrically active at all.

In other respects, EBIC images and LBIC profiles $[7,8]$ obtained on the $\mathrm{Al}$ doped samples show no recombination at grain boundaries except in specific zones (Fig. 3). This corroborates a two-fold localization for $\mathrm{Al}$ atoms in GBs : either alone, which passivates the GBs, either precipitated with $\mathrm{O}$, which activates the specific zones.

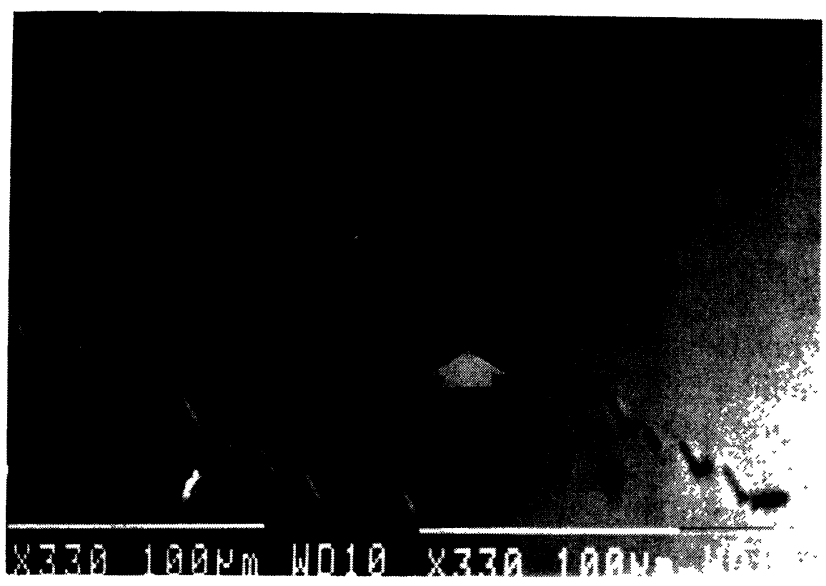

Fig. 3. - Secondary electron (left) and EBIC (right) images of a $\Sigma=3$ twin boundary. Etched zones (left) correspond to $\{111\}$ interfaces while recombination is localized on specific zones (arrowed on the right) on $\{112\}$ interfaces. Al doped E.G. HEM polysilicon $\left(N_{\mathrm{Al}}=2 \times 10^{17}\right.$ at. $\left.\mathrm{cm}^{-3}, \rho=0.17 \Omega \mathrm{cm}\right)$

$$
N_{\text {B }}=2 \times 10^{16} \text { at. } \mathrm{cm}^{-3} \text {. }
$$

\section{Carbon behaviour at grain boundaries.}

4.1 MicrostruCtURE. - The incorporation and diffusion process $[14,15]$ of carbon in the fused silicon is fairly well known for $\mathrm{Cz}$ as well as HEM polysilicon. For concentration much higher than the solubility limit the relationships between the concentration, the number of dislocations, the grain size and the minority carrier diffusion length has been determined by M. Amzil [16]. The polysilicon ingot has been prepared from UMG-Si by directional solidification with heat exchange. Metallic impurities are removed to a large extent from $90 \%$ of such ingot but the photovoltaic efficiency remains much too low $(<3 \%)$. The small resistivity $(0,04 \Omega \mathrm{cm})$ is related to a high boron concentration 
$\left(\simeq 2.5 \times 10^{18}\right.$ at. $\left.\mathrm{cm}^{3}\right)$. When starting from purified products, boron concentration should be lowered down to a few $10^{16}$ at. $\mathrm{cm}^{-3}$. Thus carbon $\left([\mathrm{C}]>4 \times 10^{17}\right.$ at. $\left.\mathrm{cm}^{-3}\right)$ as well as oxygen $\left([\mathrm{O}] \simeq 5 \times 10^{17}\right.$ at $\left.\mathrm{cm}^{-3}\right)$ should play an outstanding role. The local behaviour of carbon on structural defects (grain boundaries, stacking faults and dislocations) as well as oxygen or metallic elements was then investigated. The evolution of the defects along the ingot was considered.

The microstructure of the ingot can be divided into two zones. At the bottom ( $\simeq 20 \%$ of the ingot) the silicon grains are submillimetric. Many defects are observed. Most grain boundaries are decorated but there are also intragranular precipitates which can reach 1 or $2 \mu \mathrm{m}$ and even $10 \mu \mathrm{m}$ for $\mathrm{SiC}$ precipitates. When going up along the polycrystal growth direction, intragranular precipitates disappear completely while decorations at grain boundaries strongly diminish. The last part, representing most of the ingot $(80 \%)$ is nearly defect free. Only a few facetted boundaries $(\Sigma 3)$ are decorated.

4.2 Localization OF CARBON. - Two types of precipitates have been clearly distinguished. Cubic silicon carbides have been observed at the bottom only (Fig. 4). Their size is $>1 \mu \mathrm{m}$ they are intragranular and they come probably from a first precipitation in the liquid state. SIMS [17] and nuclear probe analysis have shown that the formation of $\mathrm{SiC}$ was correlated to oxygen precipitation. $\mathrm{Al}$ and $\mathrm{Fe}$ were also detected with $\mathrm{C}$.

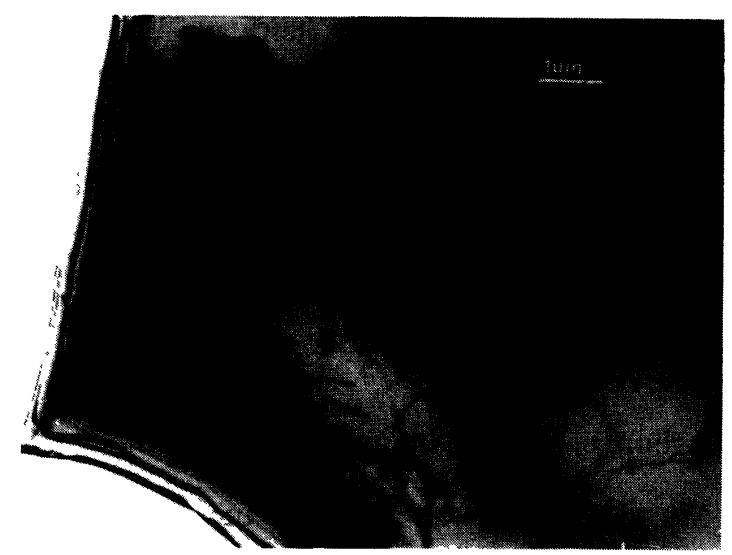

Fig. 4. - Intragranular cubic $\mathrm{SiC}$ precipitates on UMG HEM polysilicon. $\left(N_{\mathrm{B}}=2.5 \times 10^{18}\right.$ at. $\mathrm{cm}^{3}, \quad \rho=4 \times$ $\left.10^{-2} \Omega \mathrm{cm}\right) N_{\mathrm{C}}>4 \times 10^{17}$ at. $\mathrm{cm}^{-3}$.

The second type of precipitate is much more complex since electron diffraction and microdiffraction do not reveal either extra-spots from a crystalline lattice or halo rings from a non-crystalline structure (Fig. 5). High resolution structure imaging by transmission electron microscopy indicates microstrains and distortions on the segregated zones

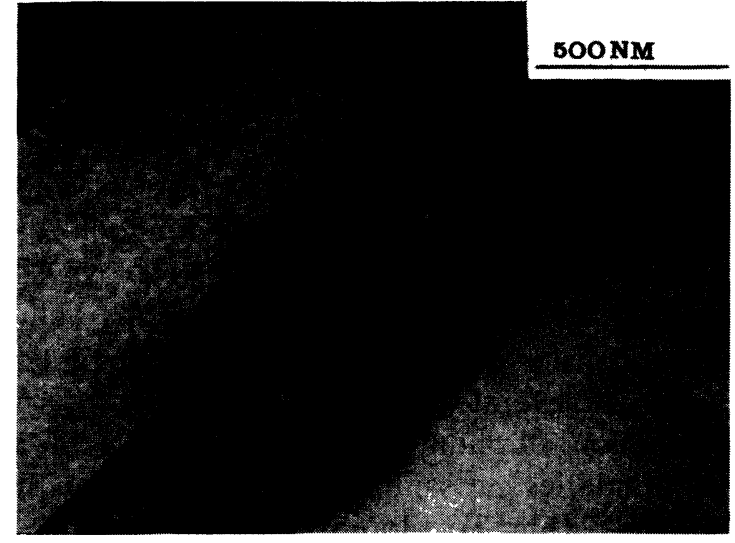

Fig. 5. - Segregated zone on a stacking fault on UMG HEM.

(Fig. 6a), as well as dislocations forming dipoles at the interfaces with the matrix (Fig. 6b). Electron energy loss spectroscopy has shown $1.0 \mathrm{wt} \% \mathrm{C}$ in these precipitates. These precipitates would correspond to areas where not only $\mathrm{C}$ but also other light atoms, in particular oxygen, sègregate. Then either by site inversions or by creating dislocations, they perturb the crystalline network, leading to elimination of channelling effects and to a larger diffuse scattering of the incident electrons in the diffraction image. It can be verified that these precipitates are fully illuminated in dark field images using either diffracted spots or the diffuse intensity. This precipitation is the only one decorating the structural defects.

4.3 Discussion. - Carbon behaves in two very distinct ways in HEM-polysilicon. Its influence related to its precipitation from the liquid state into cubic $\mathrm{SiC}$ is known [18]. In this case, its comportment is well documented. It first concerns the structure of the ingot, since the biggest precipitates act as actual nuclei for solidification and then lead to the small-grained zone. Second, it reacts on the trapping of recombining impurities such as oxygen, iron or aluminium. Carbon may also precipitate in the solid state as we have shown from the observed segregated areas. It seems likely that the electrical activity of these defects is strongly bound to the presence of $\mathrm{C}-\mathrm{O}$ complexes and to the filling of many interstitial sites.

\section{Scanning transmission electron beam induced cur- rent (STEBIC).}

Owing to the minuteness of the defects related to the segregation of $\mathrm{Al}$ as well as $\mathrm{C}$, the usual techniques do not allow to correlate locally electrical activity and microstructure in semiconductors. So with electron beam induced current in scanning electron microscopy which is the most common technique for 


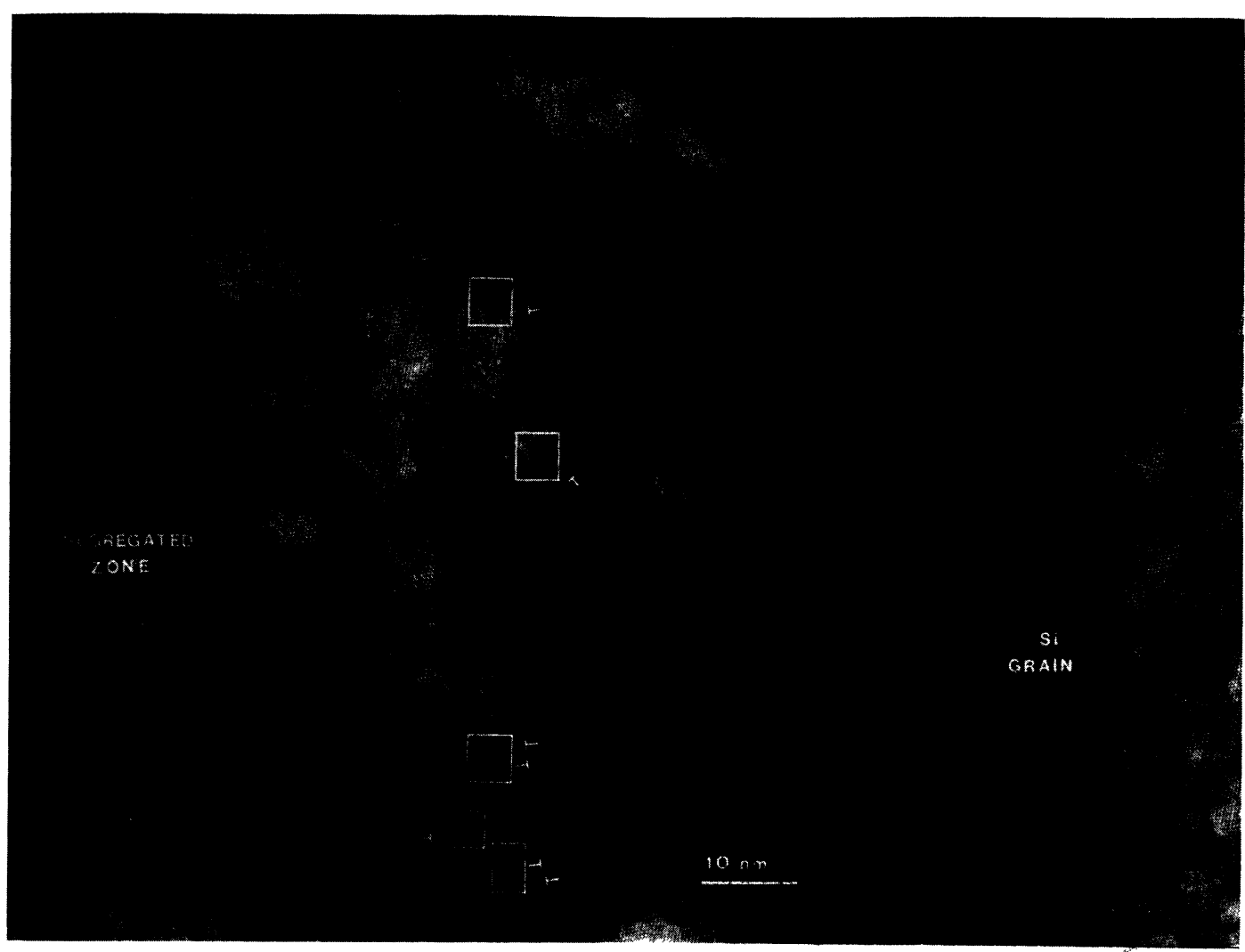

a)

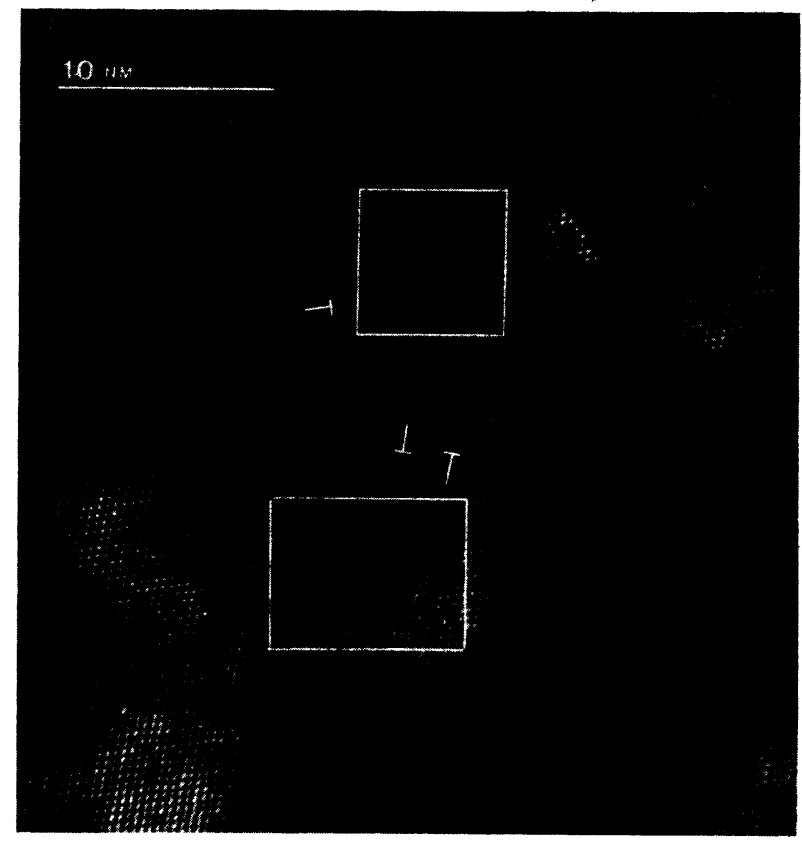

b)

Fig. 6. - High resolution structure imaging at the boundary of a segregated zone on UMG HEM polysilicon (for $N_{\mathrm{B}}$ and $N_{\mathrm{C}}$, see Fig. 5). a) Microstrains and distortions on a segregated zone. b) Dipoles at the interface.

silicon, the EBIC contrast is given by the recombination processes occurring along the path of the minority carriers between the place where they have been created and the space charge region of the diode. For instance, an electrically active grain boundary is " seen " by the electron beam when it is closer than the minority carrier diffusion length. Then the spatial resolution of conventional bulk 
EBIC is limited, for a grain boundary, to a value not much smaller than the minority carrier diffusion length $(\simeq 100 \mu \mathrm{m}$ in electronic grade $\mathrm{Si})[19,20]$. Oppositely, if scanning transmission electron beam induced current (STEBIC) is carried out on thin diodes $(0.1-1 \mu \mathrm{m})$ the electron-hole pairs are necessarily generated in the space charge region. Thus, as soon as an electron-hole pair is created, there is a competition between the recombination and the electric field of the junction. Under such conditions one may consider that the spatial resolution in STEBIC does not depend on the minority carrier diffusion length. We are developing this technique presently [8]. Figure 7 shows the data obtained on a stacking fault. The resolution is increased in a $10^{2}$ ratio compared to EBIC. The asymmetry of the STEBIC signal probably results here from the segre-

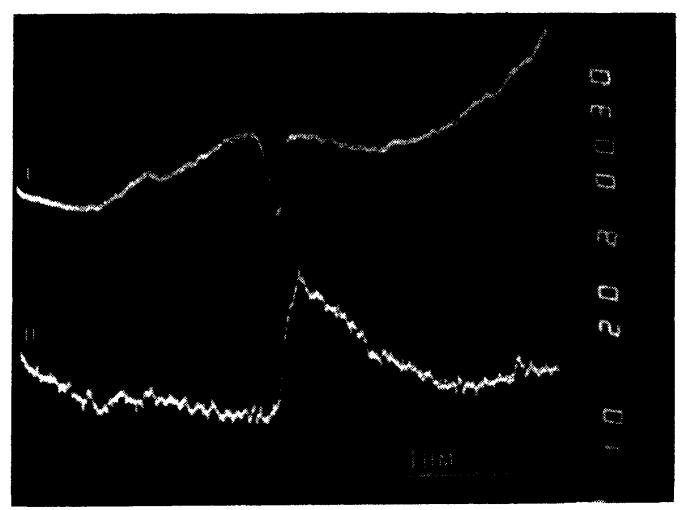

a)

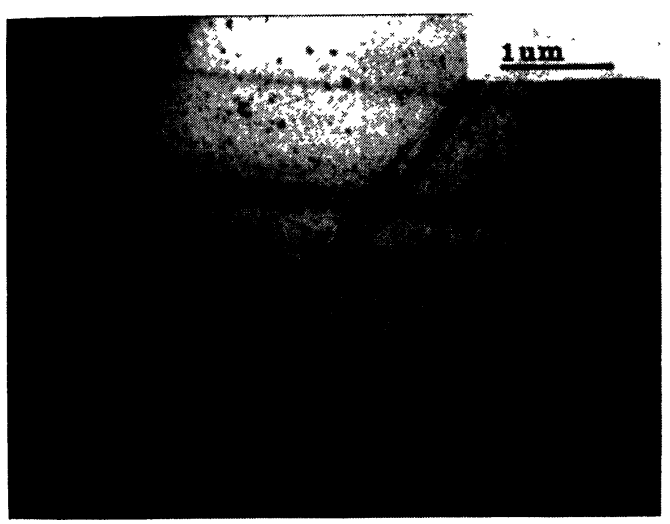

(h)

Fig. 7. - EG HEM polysilicon $\left(N_{\mathrm{B}}=3 \times 10^{6}\right.$ at. $\mathrm{cm}^{-3}$, $\rho=1.3 \Omega \mathrm{cm}) N_{\mathrm{C}}=3.3 \times 10^{17}$ at. $\mathrm{cm}^{-3}$. a) I : Intensity curve of the STEM image contrast. II : STEBIC intensity profile. The polarization of the amplifier has been reversed, the electrical activity of the stacking fault appears as a STEBIC increase. The transition corresponds to the crossing of the defect. b) Corresponding electron micrograph. gation of recombining impurities on one side of the defect as shown in figure 5. Furthermore this method allows to realize images showing the local electrical activity of decorated defects with resolution better than one $\mu \mathrm{m}$. Up to now decorated extrinsic dislocations on grain boundaries have been proved active but more results on comparative samples are needed in order to precise and refine these local informations.

\section{Conclusion.}

By combined local experiments, we have shown that general GBs act as recombinating centres as well as potential barriers. Oppositely, twin boundaries are not so easy to classify. Low order twin boundaries may behave as perfect crystal (no barrier, inactive) if they are not decorated. But if they contain decorated extrinsic dislocations they are active and some may also be resistive. Finally impurity distribution seems to play a predominant role.

Furthermore, we have emphasized the influence of light elements particularly $\mathrm{Al}$ and $\mathrm{C}$. We have shown that the comportment of $\mathrm{Al}$ is always complex. It seems that oxygen is often but not always involved and that the electrical activity may be influenced in different ways (i.e. negative or positive) depending on the localization and chemical environment of aluminium. Oppositely the electrical influence of carbon is not so ambiguous. It may act either by distorting bonds either in correlation with oxygen or by precipitating as carbide. But in any case its role will be deleterious and carbon must be discarded by all means.

The interpretation of these complex behaviours implies a precise local chemical and electrical information. We have shown that high spatial resolution combined analytical and electrical experiments in scanning and conventional transmission electron microscopy must be carried out to get this type of information. Up to now a spatial resolution of a few hundred nanometers is easily obtained for the induced current signal. It should be feasible to reach values better than $100 \mathrm{~nm}$ and to characterize easily individual defects which should allow a good understanding of electrical activity mechanism in polycrystalline silicon.

\section{Acknowledgments.}

We are grateful to G. Revel and J. L. Pastol (CNRS Vitry) for HEM polysilicon elaboration, to J. Fally (C.G.E.) for Bridgman polysilicon and to B. Pajot (Groupe de Physique du Solide Paris VII), J. E. Bourrée and M. Aucouturier (CNRS Bellevue) for IR, LBIC and SIMS characterizations. 


\section{References}

[1] Fally, J., Guenel, C., 3rd E.C. Photovoltaic Solar Energy Conf. Cannes (1980).

[2] Revel, G., Pastol, J. L., Hania, D., Nguyen Dinh HuYnh, Proc. of the 5th E.C. Photovoltaic Solar Energy Conf., Kavouri Greece (1983) p. 1037.

[3] Debrun, J. L., Prog. Cryst. Growth Character., Vol. 8, 1984.

[4] Maurice, J. L., Pastol, J. L., Bouree, J. E., LAVAl, J. Y., ReVEl, G., and Rodot, M., Poly-microcrystalline and amorphous semiconductors (Ed. de Physique, Paris) 1984, p. 323.

[5] Pajot, B., Analysis 5 (1977) 293.

[6] Mosbah, M., Metrich, N., Clocchiatti, R., Trocellier, P., Proc. 11th Intern. Conf. on Xray Optics and Microanalysis, London, Ontario (1986) (to be published by (San Francisco Press)).

[7] Maurice, J. L., Laval, J. Y., J. Physique Colloq. 43 (1982) C1-207.

[8] Maurice, J. L., Laval, J. Y., Bouree, J. E., J. Physique Colloq. 46 (1985) C4-405.

[9] Cabanel, C., Maurice, J. L., Laval, J. Y., Mat. Sc. Forum 10 (1986) 545.

[10] Maurice, J. L., Thèse $3^{\mathrm{e}}$ cycle Paris VII, 1982.

[11] Trumbore, F. A., Bell Syst. Tech. J. 39 (1960) 205.
[12] Rodot, M. and Bouree, J. E., Report «ATP photovoltaïque » and EDF contract 1B5519, October 1985.

[13] For more details on segregation processes, see : Aucouturier, M. in Polycristalline Semiconductors (Ed. G. Harbeke, Springer Verlag, Berlin) 1985 , p. 47.

[14] Schmid, F., Kattack, C. P., Digges, J. G., KaufMAN, L., J. Electrochem. Soc. (1979) 939.

[15] Endo, Y., Yatsurugi, Y., Terai, Y. and NoraKI, J. Electrochem. Soc. 126 (1983) 168.

[16] Amzil, H., Ammor, L., Psaila, E., Zehaf, M., Mathian, G., Martinuzzi, S., Crest, J. P., Oualid, J., Pichaud, B., Minary, F., J. Physique Colloq. 44 (1983) C4-415.

[17] Cabanel, C., Laval, J. Y., Pastol, J. L., Revel, G., 7th E.C. Photovoltaic Solar Energy Conference (Seville) October 1986.

[18] Blandiaux, G., Giovagnoli, A., Valladon, M., Debrun, J. L., BARRAud, J. Y., IEEE Trans. Nucl. Sci. NS-30 n² 2 (1983) 1619.

[19] Donolato, C. and Klann, H. J., J. Appl. Phys. 51 (3) (1980) 5837.

[20] Dianteill, C., Rocher, A., J. Physique Colloq. 43 (1982) $\mathrm{C} 1$. 